\title{
Effects of pandan aqueous extract on physico-chemical properties of normal and waxy rice starches
}

\author{
Pawinee Deetae ${ }^{1,2^{*}}$, Thungpon Klumrat ${ }^{2}$, Warot Nakakitwibool $^{2}$ and Atikorn Panya ${ }^{3}$ \\ ${ }^{1}$ Faculty of Agro-Industry, King Mongkut's Institute of Technology Ladkrabang, Bangkok,10520, Thailand. \\ ${ }^{2}$ Food Technology Program, Mahidol University, Kanchanaburi Campus, Saiyok, Kanchanaburi,71150, Thailand. \\ ${ }^{3}$ National Center for Genetic Engineering and Biotechnology, NSTDA, 113 Thailand Science Park, Paholyothin Road, Klong Luang, \\ Pathumthani, 12120, Thailand.
}

\begin{abstract}
Pandan aqueous extract (PAE) has traditionally been used as a food additive in Southeast Asia to enhance their flavor, color and health benefits. The purpose of this research was to investigate the effects of PAE on physico-chemical properties of normal rice starch (NRS) and waxy rice starch (WRS). Results indicate that addition of PAE significantly $(p<0.05)$ affected the physico-chemical properties of rice starches. For pasting properties, PAE significantly increased peak viscosity, breakdown and pasting temperature of NRS, while PAE decreased peak viscosity, breakdown, final viscosity and setback values of WRS. The addition of PAE to NRS and WRS significantly $(p<0.05)$ reduced gel hardness and gel adhesiveness by more than $50 \%$ compare to native control gels. The gelatinization thermal properties of both NRS and WRS were significantly $(p<0.05)$ increased when PAE was included. Only the gelatinization enthalpy of WRS was influence by the PAE. It was concluded that the addition of PAE considerably improved the thermal stability of WRS.
\end{abstract}

\section{Introduction}

Pandan (Pandanus amaryllifolius Roxb.), a member of screw pine family Pandanaceae, widely distributes in various parts of South-East Asia such as Thailand, India, Malaysia and Indonesia. The plant bears no fruits as it is sterile and is to be propagated vegetatively. Pandan leaves have a desirable characteristic aroma, that has been described as popcorn-like as in jasmine and basmati rice (1-2). Various studies have demonstrated that pandan also has other properties including antioxidant and antimicrobial activities (3-4).

In some South-East Asian countries, pandan aqueous extract has traditionally been used as a drink and/or as an additive in food products as a flavoring, green coloring as well as for helping health benefits. Some component of herb extracts, such as phenolics, may interact with other food ingredients and $\mathrm{Wu}$ et al., (5) and Xiao et al. (7) reported that physico-chemical properties of starch were affected when some herb extracts were added to food. Also Zhu et al. (6) showed that peak viscosity of wheat starch was increased in the presence of pomegranate extract, while, peak viscosity was not affect in the presence of Chinese hawthorn and gel hardness of wheat starch was reduced in the presence of green tea extract. Retrogradation of potato and maize starches was retarded more than 5 days of storage by the addition of green tea extract (7). Hence, inclusion an herb extract into a starch based food product could affect the properties during processing and end-use quality.

Non glutinous (normal) or glutinous (waxy) rice starch are important ingredients in various Thai desserts. Rice starch either from non-glutinous or glutinous varieties mainly composes of amylose and amylopectin, which its ratio is difference. The major constituent of glutinous rice starch is amylopectin and it possesses unique physical and chemical properties such as low pasting temperature and low final viscosity. In Thailand, addition of pandan aqueous extract prior to cooking rice starch based foods, especially desserts, is common, but interactions between rice starch and pandan aqueous extract have not been reported. Therefore, the aim was to investigate the effects of pandan aqueous extract on pasting, texture and gelatinization thermal properties of normal and waxy rice starches.

\section{Materials and Methods}

2.1 Material and pandan aqueous extract preparation: Normal rice starch (NRS) and waxy rice starch (WRS) were kindly supplied by Cho Heng Rice Vermicelli Factory Co. Ltd., Nakornpathom, Thailand. Pure dried pandan leaves, purchased from a local market in Kanchanaburi, Thailand, were grounded in a blender (Philips, Japan) then sieved through a No. 60 stainless steel sieve (60 meshes) and sealed in plastic bags and kept at $-80{ }^{\circ} \mathrm{C}$ until use. For preparation of pandan aqueous extract (PAE), 10 grams of pandan powder were extracted in $100 \mathrm{ml}$ of deionized water at $80^{\circ} \mathrm{C}$ for 20 min according to the method described (6) then stored at $4{ }^{\circ} \mathrm{C}$ and used within $24 \mathrm{~h}$.

2.2 Chemical compositions of starches and pandan aqueous extract (PAE): Proximate analysis of starches and pandan aqueous extract was done by using the standard methods AOAC (1990). Amylose content of rice starches was determined by Iodine Affinity method (8). Total phenolic content of PAE was measured by using the Folin-Ciocalteu assay (9). The pH of PAE was measured directly using $\mathrm{pH}$ meter (IQ, Scientific Instrument, USA). 
2.3 Pasting properties: A Rapid Visco-Analyzer (RVA model 4, Newport Scientific Australia) was used to investigate the effect of PAE on both normal and waxy rice starch pasting properties. The PAE was added to rice starch ( $3 \mathrm{~g}$ dried basis) in a RVA canister to obtain a total constant sample weight of $28 \mathrm{~g}$. The slurry was manually homogenized to prevent lump formation before the RVA run. A heating and cooling cycle was programmed in the following manner; the sample was heated from 50 to $95{ }^{\circ} \mathrm{C}$ for $7.50 \mathrm{~min}$, held at $95{ }^{\circ} \mathrm{C} 5$ min and cooled to $50^{\circ} \mathrm{C}$ within $8.50 \mathrm{~min}$, further held at $50{ }^{\circ} \mathrm{C}$ for $2 \mathrm{~min}$. The pasting properties of the sample were then recorded and presented in rapid visco units (RVU). After RVA testing, the paddle was immediately taken off and the starch paste in the canister was covered by parafilm. It was kept at $25^{\circ} \mathrm{C}$ for $48 \mathrm{~h}$ prior to texture analysis.

2.4 Texture analysis: A texture analyzer (TA-XT2i, Stable Micro Systems, Surrey, England) was used to investigate the force-time curve according to the method described (6) with some modifications. The gel was compressed by using a probe $(0.5$ HS Hemispherical plastic) at a speed of $1 \mathrm{~mm} / \mathrm{s}$ to a distance of $15 \mathrm{~mm}$. The maximum force peak in the TPA profile expressed the gel hardness and the negative area of the curve during the first retraction of the crosshead was termed adhesiveness. Springiness was measured by the distance of the detected height of the product on the second compression divided by the original compression distance. Cohesiveness was defined as the ratio of the positive force areas during the second compression to that during the first compression.

2.5 Thermal properties: Gelatinization thermal properties of samples were assessed by using a Differential Scanning Calorimeter (DSC), (Mettler Toledo, USA) as method described by Zhu et al. (6) with some modifications. Rice starch (based on dry weight) was dispersed in PAE to obtain the starch/ PAE ratio of 1:3. A $15 \mu \mathrm{g}$ sample was then transferred to an aluminum pan DSC and hermetically sealed. After equilibration at room temperature $\left(25^{\circ} \mathrm{C}\right)$ for $1 \mathrm{~h}$, the sample was heated in a DSC from $20^{\circ} \mathrm{C}$ to $100{ }^{\circ} \mathrm{C}$ at a rate of $10^{\circ} \mathrm{C} / \mathrm{min}$. The onset (To), peak (Tp), conclusion (Tc) temperatures were recorded. Gelatinization enthalpy $(\Delta \mathrm{Hg})$ was evaluated based on the area of the main endothermic peak. An empty pan was used as references for all measurements.

2.6 Statistical analysis: All experiments were carried out in triplicate. Results were reported as mean \pm standard deviation. Data analyses were performed by using the XLSTAT PRO 2012 statistical package for Windows (New York, USA). Analysis of variance (ANOVA) was performed and Duncan's multiple range test was applied on the individual variables to compare the means and to assess their significant differences ( $p<$ $0.05)$.

\section{Results and Discussion}

3.1 Chemical compositions: The amylose contents in NRS was $31.52 \pm 0.5 \%$ and in WRS $4.85 \pm 0.1 \%$ respectively. All samples contained less than $1.25 \%$ protein, less than $1.25 \%$ fat and less than $0.3 \%$ ash. These results were consistent with the results reported by Puncha-arnon et al., (10). The PAE contained 1.98\% total solids with $1.13 \%$ carbohydrate, $0.23 \%$ protein and $0.62 \%$ ash. Total phenolics in the extract was found to be $0.11 \mathrm{~g} / 100 \mathrm{ml}$ with a pH of $5.74 \pm 0.04$. Previously, it was reported that the carbohydrate in pandan leaves were mainly maltodextrin (11) and the polyphenolic in PAE were reported to be mainly gallic acid, catechin, kaempferol and naringin (12).

3.2 Pasting properties: Pasting properties can give information about starch suitability for industrial applications because it reflects changes in viscosity during processing when heated in excess water (13). Amylose content was reported to be the major factor controlling almost all physicochemical properties of rice starch including pasting and gelatinization (14). Since WRS had lower amylose content, had lower peak viscosity, peak time and pasting temperature than NRS, the physico-chemical characteristic of NRS and WRS are significantly difference (Table1). The addition of PAE significantly $(p<0.05)$ affected all pasting properties of both starches. During the heating and holding process, the mixture of NRS with PAE increased peak viscosity by up to $25 \mathrm{RVU}$ ), increased breakdown by up to $29 \mathrm{RVU}$ and increased pasting temperature values by up to $3{ }^{\circ} \mathrm{C}$ compare to NRS alone, whereas, the mixture of WRS with PAE decreased peak viscosity by up to $71 \mathrm{RVU}$, decrease breakdown by up to $26 \mathrm{RVU}$ but increase pasting temperature values by up to $11{ }^{\circ} \mathrm{C}$ compare to WRS alone. During cooling, PAE significantly $(p<0.05)$ reduced the final viscosity by approximately $50 \mathrm{RVU}$ and reduced setback values by approximately $40 \mathrm{RVU}$ for NRS and 5 RVU for WRS. The PAE used in this study contained $1.13 \%$ carbohydrate and carbohydrate such as maltodextrin may increase pasting temperature of starches in the system by reducing swelling capacity due to restriction amount of water available for starch granules (15). The PAE had a $\mathrm{pH}$ of 5.74 and acids, mainly phenolics like gallic acid in the extract, may reduce final viscosity and set back values of the starch pasting properties by destroying glyosidic bonds in starch granule (16).

3.3 Texture properties: WRS had lower hardness, adhesiveness, and springiness than NRS as shown in Table 2. Addition of PAE significantly $(p<0.05)$ reduced more than $50 \%$ gel hardness (up to $134 \mathrm{~g}$ for NRS, 22g for WRS) and gel adhesiveness (130 gs for NRS, 5 gs for WRS) but had little influence on gel springiness and gel cohesiveness. The texture properties of starch gels depend on the interaction between the disperse amylose and the continuous phase of starch (17). The presence of PAE may weaken the hydrogen boning and van der wale force of that interaction, thus altering the gel structure. 
3.4 Thermal properties: WRS had lower gelatinization onset temperature $\left(T_{0}\right)$, peak temperature $\left(T_{P}\right)$, and conclusion temperature $\left(\mathrm{T}_{\mathrm{C}}\right)$ than NRS as shown in Table 3. Addition of PAE significantly $(p<0.05)$ increased the gelatinization temperature of both NRS and WRS by up to approximately $4{ }^{\circ} \mathrm{C}$ for $\mathrm{T}_{\mathrm{o}}, \mathrm{T}_{\mathrm{P}}$ and $\mathrm{T}_{\mathrm{C}}$, while the addition of PAE significantly $(p<0.05)$ increase only the gelatinization enthalpy value $(\Delta \mathrm{H}$ gel $)$ in WRS (by up to $0.9 \mathrm{~J} / \mathrm{g}$ ). Temperature and enthalpy values were reported to be associated with the degree of crystallization of starch, amylose, amylopectin chain as well as other component present (18). The effect of PAE on the gelatinization properties of NRS and WRS might be explained by the components present in PAE such as carbohydrate, phenolic compounds could interact with water molecule, which restrict amount of water available for starch granule $(7,15)$. This require higher amount of thermal energy for gelatinization.

\section{Conclusions}

The result of this work demonstrate that the addition of pandan aqueous extract significantly affect the pasting, textural and gelatinization thermal properties of both normal and waxy rice starches with the result that pandan extract considerably improved the thermal stability of waxy rice starch. This information may provide a basic knowledge for further pandan aqueous extract application in rice starch based product.

\section{Acknowledgment}

Professor Keith Thompson, a visiting professor at Faculty of Agro-Industry, King Mongkut's Institute of Technology Ladkrabang, is gratefully acknowledged for reviewing the English language.

\section{References}

1. V. Lakanalamai S., Ilangantileke, Cereal Chem, 70, 381-384 (1993).

2. RG. Buttery, BO. Juliano, LC. Ling, Chem Ind. 23, 478-479 (1983).

3. S.W. Yan, R. Asmah, Int Food Res J. 17, 417-423 (2010).

4. A.F. Faras, S.S. Wadkar, J.S. Ghosh. Int Food Res J. 21,421-423 (2014).

5. Y. Wu, Z. Chen, X. Li and Mei Li, Food Res Int., 42, 221-225 (2009).

6. F. Zhu, Y.Z. Cai, M. Sun, H. Corke, Food Chem., 112, 919-923 (2009).

7. H. Xiao, Q. Lin, G.Q. Liu, Y. Wu, W. Wu, X. Fu, Food Bioprocess Technol. Chem., 6, 2177-2183 (2013).

8. C.A. Knutson, Cereal Chem., 63, 89-92. (1986).

9. P. Deetae, P. Parichanon, P. Trakunleewatthana, P., C. Chanseetis, S. Lertsiri, Food Chem., 133, 953-959 (2012).

10. S. Puncha-arnon, D. Uttapap, Carbohyd Polym.,
91, 85-91 (2013).

11. S. Chaiseri, V. Cheetangdee, Kaset J Nat Sci. 40, 67-74 (2006).

12. A. Ghasemzadeh, HZ. Jaafar, BMC Complement Altern Med., 13, 341, (2013).

13. J. Ahmed, L. Thomas, A. Taher, A. Joseph, Carbohydr. Polym. 152, 639-647 (2016).

14 HAM. Wickramasinghe, T. Noda, Food Sci Technol Res., 14, 49-54 (2008).

15. L. Juszczak, D. GaBkowska, T. Witczak, T. Fortuna, Int. J. Food Sci. 2013, (2013).

16. F. Zhang, M. Liu, F. Mo, M. Zhang, J. Zheng Polymers. 9, 695 (2017).

17. S.G., Ring. Starch/Stärke, 37, 80-83 (1985)

18. M.B. Cardoso, J. L. Putaux, D. Samios, D., Samios, D., N.P. Silveira. Carbohydr. Polym., 70, 160-165 (2007). 
Table 1: Pasting properties of normal rice starch (NRS) and waxy rice starch (WRS) with and without pandan aqueous extract (PAE)

\begin{tabular}{|l|c|c|c|c|c|c|}
\hline \multirow{2}{*}{ Samples } & \multicolumn{5}{|c|}{ Pasting properties } \\
\cline { 2 - 7 } & $\begin{array}{c}\text { Peak Time } \\
\text { (Min) }\end{array}$ & $\begin{array}{c}\text { Peak } \\
\text { viscosity } \\
(\text { RVU) }\end{array}$ & $\begin{array}{c}\text { Breakdown } \\
(\text { RVU) }\end{array}$ & $\begin{array}{c}\text { Final Viscosity } \\
\text { (RVU) }\end{array}$ & $\begin{array}{c}\text { Setback } \\
(\text { RVU) }\end{array}$ & $\begin{array}{c}\text { Pasting } \\
\text { Temperature } \\
\left({ }^{*} \text { C) }\right.\end{array}$ \\
\hline NRS & $9.60 \pm 0.00^{\mathrm{a}}$ & $357.67 \pm 0.50^{\mathrm{a}}$ & $133.30 \pm 1.37^{\mathrm{a}}$ & $419.25 \pm 2.61^{\mathrm{a}}$ & $194.89 \pm 1.54^{\mathrm{a}}$ & $79.40 \pm 0.23^{\mathrm{a}}$ \\
\hline NRS+ PAE & $9.47 \pm 0.04^{\mathrm{b}}$ & $382.72 \pm 1.65^{\mathrm{b}}$ & $162.28 \pm 2.54^{\mathrm{b}}$ & $371.39 \pm 3.48^{\mathrm{b}}$ & $150.95 \pm 0.70^{\mathrm{b}}$ & $81.78 \pm 0.16^{\mathrm{b}}$ \\
\hline WRS & $5.18 \pm 0.03^{\mathrm{c}}$ & $345.11 \pm 1.65^{\mathrm{c}}$ & $188.83 \pm 1.50^{\mathrm{c}}$ & $201.31 \pm 1.76^{\mathrm{c}}$ & $45.03 \pm 1.69^{\mathrm{c}}$ & $63.58 \pm 0.04^{\mathrm{c}}$ \\
\hline WRS+ PAE & $5.87 \pm 0.04^{\mathrm{d}}$ & $273.47 \pm 0.54^{\mathrm{d}}$ & $162.97 \pm 0.57^{\mathrm{b}}$ & $151.31 \pm 0.96^{\mathrm{d}}$ & $40.80 \pm 0.48^{\mathrm{d}}$ & $75.20 \pm 0.17^{\mathrm{d}}$ \\
\hline
\end{tabular}

Values are means \pm SD $(n=3)$. Mean $( \pm$ SD) with different superscript letters $(a, b, c d)$ in the same column indicate significant differences $(\mathrm{p}<0.05)$.

Table 2: Texture properties of normal rice starch (NRS) and waxy rice starch (WRS) with and without pandan aqueous extract (PAE)

\begin{tabular}{|l|c|c|c|c|}
\hline \multirow{2}{*}{ Samples } & \multicolumn{4}{|c|}{ Texture properties } \\
\cline { 2 - 5 } & $\begin{array}{c}\text { Hardness } \\
(\text { g) }\end{array}$ & $\begin{array}{c}\text { Adhesiveness } \\
(\text { gs })\end{array}$ & Springiness & Cohesiveness \\
\hline \multirow{2}{*}{ NRS } & $240.24 \pm 6.53^{\mathrm{a}}$ & $143.00 \pm 29.48^{\mathrm{a}}$ & $1.56 \pm 0.15^{\mathrm{a}}$ & $0.41 \pm 0.03^{\mathrm{b}}$ \\
\hline \multirow{2}{*}{ NRS + PAE } & $106.12 \pm 16.70^{\mathrm{b}}$ & $12.71 \pm 8.03^{\mathrm{b}}$ & $2.06 \pm 0.43^{\mathrm{a}}$ & $0.46 \pm 0.07^{\mathrm{ab}}$ \\
\hline WRS & $32.60 \pm 2.72^{\mathrm{c}}$ & $8.00 \pm 2.98^{\mathrm{b}}$ & $0.98 \pm 0.02^{\mathrm{c}}$ & $0.43 \pm 0.03^{\mathrm{ab}}$ \\
\hline WRS+PAE & $10.26 \pm 0.23^{\mathrm{d}}$ & $2.80 \pm 0.47^{\mathrm{b}}$ & $1.15 \pm 0.09^{\mathrm{b}}$ & $0.48 \pm 0.01^{\mathrm{a}}$ \\
\hline
\end{tabular}

Values are means \pm SD $(n=3)$. Mean $( \pm$ SD) with different superscript letters $(a, b, c d)$ in the same column indicate significant differences $(\mathrm{p}<0.05)$.

Table 3: Gelatinization temperatures and enthalpy of normal rice starch (NRS) and waxy rice starch (WRS) with and without pandan aqueous extract (PAE)

\begin{tabular}{|l|c|c|c|c|}
\hline Samples & To $(\circ \mathbf{C})$ & Tp $(\circ \mathbf{C})$ & Tc $\left({ }^{\circ} \mathbf{C}\right)$ & $\Delta \mathbf{H}$ gel $(\mathbf{J} / \mathbf{g})$ \\
\hline NRS & $72.35 \pm 0.07^{\mathrm{a}}$ & $77.30 \pm 0.15^{\mathrm{a}}$ & $81.92 \pm 0.12^{\mathrm{a}}$ & $12.51 \pm 0.06^{\mathrm{a}}$ \\
\hline NRS + PAE & $76.64 \pm 0.25^{\mathrm{b}}$ & $81.13 \pm 0.18^{\mathrm{b}}$ & $85.49 \pm 0.15^{\mathrm{b}}$ & $12.31 \pm 0.34^{\mathrm{a}}$ \\
\hline WRS & $60.13 \pm 0.25^{\mathrm{c}}$ & $67.60 \pm 0.27^{\mathrm{c}}$ & $75.12 \pm 0.34^{\mathrm{c}}$ & $13.62 \pm 0.13^{\mathrm{a}}$ \\
\hline WRS+ PAE & $63.88 \pm 0.10^{\mathrm{d}}$ & $71.27 \pm 0.18^{\mathrm{d}}$ & $78.48 \pm 0.08^{\mathrm{d}}$ & $14.54 \pm 0.25^{\mathrm{b}}$ \\
\hline
\end{tabular}

To, Onset temperature; Tp, Peak temperature; Tc, Conclusion temperature; $\Delta \mathrm{H}_{\text {gel }}$, gelatinization enthalpy. Values are means \pm SD $(n=3)$. Means $( \pm$ SD) with different superscript letters $(a, b, c$ and $d)$ in the same column indicate significant differences $(p<0.05)$ 